\title{
Anti-ILT4 Monoclonal Antibody MK-4830
}

National Cancer Institute

\section{Source}

National Cancer Institute. Anti-ILT4 Monoclonal Antibody MK-4830. NCI Thesaurus. Code C160204.

A human monoclonal antibody directed against the inhibitory immune checkpoint receptor immunog lobulin-like transcript 4 (ILT 4; leukocyte immunoglobulin-like receptor subfamily B member 2; LILRB2; lymphocyte immunoglobulin-like receptor 2; LIR2; monocyte/macrophage immunog lobulin-like receptor 10; MIR-10; CD85d), with potential immunomodulating and antineoplastic activities. Upon administration, anti-ILT4 monoclonal antibody MK-4830 targets and binds to ILT4. This prevents the binding of ILT 4 ligands to their receptor and prevents ILT4-mediated signaling. This abrog ates the immunosuppressive activities of ILT4 in the tumor microenvironment (TME), activates the expression of pro-inflammatory cytokines, including GM-CSF and tumor necrosis factor alpha (TNFalpha), and enhances a cytotoxic T-lymphocyte (CTL)-mediated antitumor immune response. ILT4, plays a key role in tumor immune evasion. ILT4, a transmembrane protein and inhibitory member of the immunoglobulin-like transcript (ILT) family of proteins, is expressed primarily by myeloid cells, including monocytes, macrophages, dendritic cells (DCs) and granulocytes, and certain tumor cells. 